University of Warwick institutional repository: http://go.warwick.ac.uk/wrap This paper is made available online in accordance with publisher policies. Please scroll down to view the document itself. Please refer to the repository record for this item and our policy information available from the repository home page for further information.

To see the final version of this paper please visit the publisher's website. Access to the published version may require a subscription.

Author(s): SAFFRON KARLSEN, JAMES Y. NAZROO, KWAME MCKENZIE, KAMALDEEP BHUI and SCOTT WEICH

Article Title: Racism psychosis and common mental disorder among ethnic minority groups in England

Year of publication: 2005

Link to published

version: http://dx.doi.org/10.1017/S0033291705005830

Publisher statement: None 


\title{
Racism, psychosis and common mental disorder among ethnic minority groups in England
}

\author{
SAFFRON KARLSEN ${ }^{1 *}$, JAMES Y. NAZROO ${ }^{1}$, KWAME MCKENZIE ${ }^{2}$, \\ KAMALDEEP BHUI ${ }^{3}$ AND SCOTT WEICH ${ }^{4}$ \\ ${ }^{1}$ Department of Epidemiology and Public Health, University College London; ${ }^{2}$ Department of Psychiatry and \\ Behavioural Sciences, Royal Free and University College Medical School, University College London; \\ ${ }^{3}$ Centre for Psychiatry, Barts \& The London School of Medicine, Queen Mary, University of London; \\ ${ }^{4}$ Division of Health in the Community, Warwick Medical School (LWMS), University of Warwick, UK
}

\begin{abstract}
Background. The aim of this study was to explore the relationship between risk of psychosis, common mental disorder (CMD) and indicators of racism among ethnic minority groups in England and how this relationship may vary by particular ethnic groups.

Method. A multivariate analysis was carried out of quantitative, cross-sectional data from a nationally representative community sample of people aged between 16 and 74 years from the largest ethnic minority groups in England: those of Caribbean, Indian, Pakistani, Bangladeshi and Irish origin.

Results. Experience of interpersonal racism and perceiving racism in the wider society each have independent effects on the risk of CMD and psychosis, after controlling for the effects of gender, age and socio-economic status. There was some variation in the findings when they were conducted for separate ethnic and gender groups.
\end{abstract}

Conclusions. An understanding of the relationship between racism and mental health may go some way towards explaining the ethnic variations found in both CMD and, particularly, psychosis.

\section{INTRODUCTION}

Studies have reported higher incidence rates of psychosis among ethnic minority groups in the UK compared with British white groups, particularly among populations of African or Caribbean origin (King et al. 1994; Van Os et al. 1996; Bhugra et al. 1997). The results of incidence and prevalence studies of other mental illnesses and of community-based prevalence studies of psychosis have been mixed (Berthoud \& Nazroo, 1997; Nazroo, 1997; Nazroo \& King, 2002; King et al. 2005). The best studied discrepancy is the high rate of treatment for psychosis found among people of Caribbean origin residing in the UK. This increase is not

* Address for correspondence: Saffron Karlsen, Department of Epidemiology and Public Health, University College London, 1-19 Torrington Place, London WC1E 6BT, UK.

(Email: s.karlsen@ucl.ac.uk) mirrored by rates in the Caribbean, however (Hickling \& Rodgers-Johnson, 1995; Bhugra et al. 1996; Mahy et al. 1999).

Sharpley and co-workers (2001), in a review of the current hypotheses employed to explain this supposed excess, suggest four groups of hypotheses related to:

(1) cultural factors that may lead to misdiagnosis, including the impact of attitudes of British psychiatrists as well as ethnic differences in the presentation of particular symptoms;

(2) biological hypotheses, including genetic predisposition to mental ill-health, and factors related to birth, childhood, migration, or health behaviours;

(3) social or structural hypotheses, including the effect of living in deprived inner-city areas, neighbourhood social disadvantage 
(with an associated affect on social cohesion), racism, and ethnic differences in pathways to and attitudes towards care;

(4) psychological hypotheses, such as the interpretation of life events and attributional style.

They conclude that no simple hypothesis can explain the associations found between African or Caribbean ethnicity and psychosis, but also that 'the preliminary findings... point towards social and cognitive factors' (Sharpley et al. 2001: 65). Similarly, van Os and colleagues using data on first admission rates for operationally defined schizophrenia and other psychosis in a South London hospital, found a 'non-specific increase in psychosis among various groups of ethnic minorities [which] would appear to indicate that common sources of stress on members of ethnic minorities, such as cultural adjustment, discrimination, impact of migration and racism, are ... important determinants.' (van Os et al. 1996: 207). Speculative explanations for ethnic differences in treated psychosis (van Os et al. 1996; Sharpley et al. 2001) suggest that the stress associated with living in, in this case, England promotes the development of psychosis and potentially other mental health problems among people from ethnic minority groups (Sugarman \& Craufurd, 1994; McKenzie et al. 1995; Mahy et al. 1999; Boydell et al. 2001). One possible cause of such stress that has remained largely unexplored is the impact of racism outside mental health services, in particular whether the experience of racism in everyday life may predispose an individual towards mental health problems.

While there are several studies which suggest a potential influence for racism on mental health problems (Williams \& Hunt, 1997; Janssen et al. 2003), research in the UK has provided little empirical research evidence exploring associations between experiences of racism and mental ill health (Chakraborty \& McKenzie, 2002). Earlier exploration of the impact of selfreported experiences of racial harassment and perceptions of Britain as a 'racist society', using population-based data on people from ethnic minority groups included in the Fourth National Survey of Ethnic Minorities (FNS), found that those reporting to have experienced some form of physical racial attack had a prevalence of depression almost three times and a prevalence of psychosis almost five times that of people reporting no harassment (Karlsen \& Nazroo, 2002), while the prevalence of psychosis was $57 \%$ higher among those who believed that the majority of British employers would discriminate against someone on the grounds of race, religion, culture or ethnicity. Unfortunately, the FNS sample was too small to explore the effects of racism on mental health in specific ethnic minority groups and did not include people from white ethnic minority groups who may be victims of racism, such as Irish groups in the UK. Cultural, socioeconomic and gender factors may compound or negate the effects of racial discrimination on health and so investigating associations in specific ethnic groups is important.

The data used in this paper provide us with a unique opportunity to explore the relationship between racism and indicators of mental health for Caribbean, Indian, Bangladeshi, Pakistani and Irish people living in England. We aim to use these data to replicate the earlier findings suggesting an association between common mental disorders and psychosis and racism (Karlsen \& Nazroo, 2002) and to investigate whether and how these associations vary by particular ethnic and gender groups, and whether the relationship between mental ill health and racism may be attenuated by gender, age or socio-economic status.

\section{METHOD}

We undertook analysis of cross-sectional quantitative data collected as part of the Ethnic Minority Psychiatric Illness Rates in the Community (EMPIRIC) study (Sproston $\&$ Nazroo, 2002). EMPIRIC was a follow-up survey of different ethnic minority populations living in England, who took part in the 1999 Health Survey for England (HSE) (Erens et al. 2001), together with a white English sample from the 1998 HSE. All HSE 1999 respondents aged 16-74 from the Caribbean, Indian, Pakistani, Bangladeshi and Irish groups and who agreed to be recontacted were included in the sample. The sample for this analysis comprised: 733 Irish, 691 Caribbean, 650 Bangladeshi, 648 Indian and 724 Pakistani 
people. Respondents were allocated into an ethnic group on the basis of answers to a question on their family origins which correlates highly with the classificatory system used in the 1991 British census (HMSO, 1992; Nazroo, 1997). The data were collected using a structured questionnaire in the language(s) of the respondent's choice.

The HSE sampling procedures were designed to select probability samples of both individuals and households. Sampling points for the ethnic minority sample were identified using information from the 1991 Census (HMSO, 1992), which allowed areas to be selected on the basis of the concentration of ethnic minority people within them. Areas with low concentrations of ethnic minority people were also identified and included. Screening for non-white ethnic minority respondents in areas with few ethnic minority residents was carried out using focused enumeration (Brown \& Richie, 1982; Smith \& Prior, 1997). It was not used to identify people of Irish origin who were determined only at the visited address.

The overall response rate for the EMPIRIC study was $68 \%$. The sample experienced two waves of non-response, at the HSE and at EMPIRIC. The HSE surveys are not usually weighted because the sampling process produces an equal probability of selection for all eligible respondents. However, the ethnic minority boost in the 1999 HSE meant that the sample had to be weighted to correct for the unequal probabilities of selection for different classes of respondents. Three sets of weights were required for the HSE99 data, to correct for (i) unequal probabilities of selection for postcode sectors; (ii) unequal probability of household selection within sectors; and (iii) varying probabilities of selection of adults within participating households. Weights were inversely proportional to the selection probabilities for postcode sectors, addresses, and number of adults living in participating households, respectively. These weightings were retained in the EMPIRIC analysis and, in addition, weights were applied to adjust for the non-response to the EMPIRIC survey. These non-response weights were obtained using regression modelling, based on HSE data for EMPIRIC informants and non-informants. All standard errors and confidence intervals were also corrected for auto-correlation within the stratified multi-stage design (Sproston \& Nazroo, 2002).

This analysis employed three indicators of racism. The first asked respondents about experiences of interpersonal racism within the last year, coded as: no experience, experience of any racist verbal attack, and experience of any racist physical attack on the respondent or their property. The second question asked respondents if they felt they had ever been refused a job or been treated unfairly at work with regard to promotion or a move to a better position for reasons to do with race, colour, religion or ethnic background, coded as yes or no. The third question explored respondents' perceptions of racism in the UK more generally, asking respondents what proportion of British employers they felt would refuse someone employment on the grounds of race, colour, religion or cultural background, coded as none, a few, about half, and more than half.

While these variable codings were employed in the initial models, which combined all respondents from ethnic minority groups, the models exploring each ethnic minority group separately dichotomized two of the variables to reduce the analytical problems produced by the smaller sample sizes. The variable asking respondents about experiences of interpersonal racism was coded 'no' and 'any' experience of racist abuse or assault. The question asking what proportion of British employers respondents felt would refuse someone employment was coded as 'none/a few' and 'half or more'.

The mental health outcomes used were: the risk of reaching the case threshold for a common mental disorder (CMD) (anxiety disorder or depression) in the previous week and an estimate of the annual prevalence of psychosis. The presence of CMD was assessed using the Revised Clinical Interview Schedule (CIS-R) (Lewis et al. 1992), which collects data on symptoms of common mental disorder and derives psychiatric diagnoses according to the International Classification of Diseases, 10th edition (Goldberg et al. 1970; Lewis et al. 1992). The CIS-R asks about the presence and severity of 14 non-psychotic psychiatric symptoms during the week prior to interview. For the purposes of this analysis the CIS-R score was analysed as a dichotomous variable, using a case threshold of $\geqslant 12$ (Lewis et al. 1992). 
Estimated annual prevalence of psychosis in a particular population was calculated using an algorithm based on responses to the Psychosis Screening Questionnaire (PSQ), which screens for symptoms commonly found in psychotic disorders (Bebbington \& Nayani, 1995). We used the PSQ as it was used in the OPCS/ONS series of surveys (Singleton et al. 2001) and the FNS (Nazroo, 1997), which meant that all stem questions were asked of all respondents, regardless of their answers to previous PSQ questions. The PSQ covers five broad categories of symptoms: hypomania; thought interference; delusions of persecution; a feeling that something 'strange' is taking place that is hard to explain; and auditory hallucinations. Two or three questions cover each symptom category; a general introductory stem question and one or two more targeted questions for those who answer 'yes' to the introductory questions. The informant must answer 'yes' to all questions within a symptom category in order to screen positive on that item. In the standard use of the PSQ, informants are not asked to continue once they have answered positively to one item, as they are entered into a more detailed clinical assessment. However, as we did not conduct clinical assessments, informants were asked all of the stem questions.

Findings from the clinical interviews conducted as part of the FNS showed that the higher the number of positive PSQ items, the greater the risk of meeting the criteria for psychotic illness in a clinical validation interview (Nazroo, 1997). Table 1 shows these findings in terms of the relationship between PSQ score and diagnostic class at clinical interview using the Present State Examination (Wing et al. 1974) for informants from all ethnic groups (Nazroo \& King, 2002). This allowed us to estimate the risk of a psychosis diagnosis on the basis of PSQ score at the individual level and thereby estimate the prevalence of psychosis within sub-groups in the sample (Berthoud \& Nazroo, 1997; Nazroo, 1997; Nazroo \& King, 2002). It is important to emphasize that this study collected no information from which we may infer directly the prevalence of psychosis, and uses only this indirect estimate of risk. Increased scores on this measure can therefore only indicate an increased risk of psychosis, which may not translate to an increase in actual diagnoses at the
Table 1. Number of positive Psychosis Screening Questionnaire (PSQ) items and Present State Examination (PSE) diagnostic class (Nazroo \& King, 2002)

\begin{tabular}{lccc}
\hline \hline & \multicolumn{2}{c}{ Number of positive PSQ items } \\
\cline { 2 - 4 } & $\begin{array}{c}\text { One } \\
(\%)\end{array}$ & $\begin{array}{c}\text { Two } \\
(\%)\end{array}$ & $\begin{array}{c}\text { Three or } \\
\text { more }(\%)\end{array}$ \\
\hline PSE diagnostic class & & & \\
$\quad$ None & $31 \cdot 3$ & $16 \cdot 4$ & $21 \cdot 7$ \\
Neurotic & $56 \cdot 0$ & $62 \cdot 3$ & $56 \cdot 5$ \\
Affective psychosis & $2 \cdot 2$ & $4 \cdot 9$ & $4 \cdot 4$ \\
$\quad$ Non-affective psychosis & $10 \cdot 5$ & $16 \cdot 4$ & $17 \cdot 4$ \\
$n \quad$ & 134 & 61 & 23 \\
\hline \hline
\end{tabular}

individual level, in much the same way as checklist measures of CMD (such as the CIS-R) operate.

We performed a series of regression analyses to explore the independent associations between the three indicators of racism, which were jointly included in the models, and each of the two indicators of mental health. The multivariate analyses were conducted for men and women separately, as well as combined. Models were adjusted for age, household occupational class and current employment status, and gender (where appropriate).

\section{RESULTS}

The estimated annual prevalence of psychosis was 6 per thousand for Bangladeshi people, 10 per thousand for Irish and Indian people, 13 per thousand for Pakistani people and 16 per thousand for Caribbean people (Nazroo \& King, 2002; King et al. 2005). Around a quarter of Pakistani and Indian women, one-fifth of Caribbean and Irish women and one in eight Bangladeshi women reached the case threshold for CMD, differences that were statistically significant (Weich \& McManus, 2002; Weich et al. 2004). Between one in six and one in nine men reached the case threshold for CMD.

Caribbean people were most likely to report having experience of racial harassment, followed by Pakistani and Indian, then Bangladeshi and Irish people (Table 2). Responses to the question enquiring about employment-related discrimination followed a similar pattern, with $36 \%$ of Caribbean, $19 \%$ of 
Table 2. Racial discrimination and harassment by ethnic minority group

\begin{tabular}{|c|c|c|c|c|c|c|c|}
\hline & \multicolumn{5}{|c|}{ Ethnic group } & \multirow[b]{2}{*}{$p$ value } & \multirow[b]{2}{*}{$\chi^{2}$} \\
\hline & Irish & Caribbean & Bangladeshi & Indian & Pakistani & & \\
\hline $\begin{array}{l}\text { Experienced racism within the } \\
\text { last year }(\%)\end{array}$ & & & & & & $<0 \cdot 01$ & $95 \cdot 3$ \\
\hline No & 93 & 85 & 91 & 87 & 87 & & \\
\hline Verbal only & 6 & 13 & 7 & 10 & 10 & & \\
\hline Physical & 1 & 2 & 2 & 2 & 3 & & \\
\hline Weighted bases & 3313 & 826 & 274 & 1157 & 725 & & \\
\hline Unweighted bases & 733 & 694 & 650 & 643 & 724 & & \\
\hline $\begin{array}{l}\text { Experienced employment- } \\
\text { related discrimination (yes) }(\%)\end{array}$ & 7 & 36 & 8 & 19 & 16 & $<0.01$ & $524 \cdot 0$ \\
\hline Weighted bases & 3313 & 825 & 274 & 1156 & 724 & & \\
\hline Unweighted bases & 733 & 694 & 650 & 643 & 724 & & \\
\hline British employers are racist $(\%)$ & & & & & & $<0 \cdot 01$ & $838 \cdot 7$ \\
\hline None & 15 & 11 & 65 & 36 & 36 & & \\
\hline A few & 71 & 54 & 24 & 43 & 44 & & \\
\hline About half & 13 & 27 & 9 & 17 & 15 & & \\
\hline Most & 2 & 8 & 3 & 4 & 5 & & \\
\hline Weighted bases & 3158 & 778 & 257 & 1098 & 669 & & \\
\hline Unweighted bases & 696 & 657 & 611 & 614 & 676 & & \\
\hline
\end{tabular}

Indian, $16 \%$ of Pakistani compared with $7 \%$ and $8 \%$ of Irish and Bangladeshi people, respectively, reporting having experienced such discrimination at some point in their lives. Over one-third of Caribbean people, around $20 \%$ of Pakistani and Indian people, $15 \%$ of Irish people and $12 \%$ of Bangladeshi people believed half or more of British employers would racially discriminate against someone.

Table 3 reports the findings from logistic regression analyses (for all ethnic minority groups combined) exploring associations between racism and risk of reaching the case threshold for CMD and estimated prevalence of psychosis, for men and women separately and combined. Experience of verbal abuse, physical assault, workplace discrimination, and perceiving British employers to be racist were included in the models together, and all showed some independent statistically significant association with risk of CMD, with those experiencing verbal abuse or physical assault having over twice the risk of CMD of those reporting no harassment. There was also a $50 \%$ increased risk of CMD among those reporting experience of employment-related discrimination. Reporting a belief that a few or more British employers are racist was also associated with an increased risk of CMD. This pattern was repeated in the separate gender models.

Risk of psychosis was also significantly associated with experience of verbal abuse, physical assault and workplace discrimination in the all-ethnic-minority-groups model (Table 3). Reported experience of verbal abuse or physical assault was associated with over twice the risk of psychosis of those reporting no experience in the combined gender models, with similar patterns for the gender-specific models. Experience of work-place discrimination and believing that more than half of British employers would racially discriminate against someone both appeared to be associated with an increased risk of psychosis, but these differences were not significant.

Table 4 reports findings for the logistic regression analyses exploring associations between the different indicators of racism and risk of reaching the case threshold for CMD and estimated prevalence of psychosis for each ethnic minority group separately (with men and women combined). Reporting any raciallymotivated abuse or assault in the last year was associated with between a two- and three-fold increased risk of CMD among each of the ethnic minority groups, with the exception of Bangladeshi people. Reporting experience of employment-related discrimination was associated with between a two- and three-anda-half-times increased risk of CMD among each of the ethnic minority groups, with the exception of Pakistani people. Perceiving half or more of British employers to be racist appeared to have a varying effect on risk of 
Table 3. Odds ratios for associations between estimated weekly prevalence of common mental disorders (CMD), psychosis and indicators of racism (all ethnic minority groups combined, standardized for age, gender and socio-economic status)

\begin{tabular}{|c|c|c|}
\hline & $\begin{array}{l}\text { Estimated weekly } \\
\text { prevalence } \\
\text { of CMD }\end{array}$ & $\begin{array}{c}\text { Estimated annual } \\
\text { prevalence of } \\
\text { psychosis }\end{array}$ \\
\hline \multicolumn{3}{|l|}{ Men only } \\
\hline \multicolumn{3}{|c|}{ Racial harassment } \\
\hline None & $1 \cdot 00$ & $1 \cdot 00$ \\
\hline Verbal & $2 \cdot 16(1 \cdot 13-4 \cdot 10)$ & $2 \cdot 21(1 \cdot 13-4 \cdot 33)$ \\
\hline Physical & $2 \cdot 10(0 \cdot 60-7 \cdot 42)$ & $3.09(0 \cdot 87-10 \cdot 95)$ \\
\hline \multicolumn{3}{|c|}{$\begin{array}{l}\text { Employment-related } \\
\text { discrimination }\end{array}$} \\
\hline No & $1 \cdot 00$ & $1 \cdot 00$ \\
\hline Yes & $1 \cdot 33(0 \cdot 80-2 \cdot 21)$ & $1 \cdot 26(0 \cdot 71-2 \cdot 23)$ \\
\hline \multicolumn{3}{|l|}{$\begin{array}{l}\text { British employers } \\
\text { are racist }\end{array}$} \\
\hline No & $1 \cdot 00$ & $1 \cdot 00$ \\
\hline A few & $1 \cdot 45(0 \cdot 85-2 \cdot 45)$ & $0.95(0 \cdot 48-1 \cdot 89)$ \\
\hline About half & $2 \cdot 27(1 \cdot 15-4 \cdot 49)$ & $0 \cdot 87(0 \cdot 35-2 \cdot 16)$ \\
\hline More than half & $2 \cdot 62(1 \cdot 09-6 \cdot 30)$ & $1 \cdot 29(0 \cdot 48-3 \cdot 44)$ \\
\hline \multicolumn{3}{|l|}{ Women only } \\
\hline \multicolumn{3}{|c|}{ Racial harassment } \\
\hline None & $1 \cdot 00$ & $1 \cdot 00$ \\
\hline Verbal & $2 \cdot 17(1 \cdot 24-3 \cdot 79)$ & $2 \cdot 26(1.07-4 \cdot 76)$ \\
\hline Physical & $5 \cdot 04(1 \cdot 84-13 \cdot 83)$ & $3 \cdot 17(0 \cdot 89-11 \cdot 35)$ \\
\hline \multicolumn{3}{|c|}{$\begin{array}{l}\text { Employment-related } \\
\text { discrimination }\end{array}$} \\
\hline No & $1 \cdot 00$ & $1 \cdot 00$ \\
\hline Yes & $1 \cdot 67(1 \cdot 05-2 \cdot 65)$ & $1 \cdot 59(0 \cdot 79-3 \cdot 19)$ \\
\hline \multicolumn{3}{|l|}{$\begin{array}{l}\text { British employers } \\
\text { are racist }\end{array}$} \\
\hline No & $1 \cdot 00$ & $1 \cdot 00$ \\
\hline A few & $1 \cdot 03(0 \cdot 67-1 \cdot 57)$ & $1 \cdot 07(0 \cdot 53-2 \cdot 16)$ \\
\hline About half & $1 \cdot 71(1 \cdot 00-2 \cdot 91)$ & $1 \cdot 07(0 \cdot 47-2 \cdot 44)$ \\
\hline More than half & $1 \cdot 80(0 \cdot 90-3 \cdot 58)$ & $2 \cdot 39(0 \cdot 92-6 \cdot 23)$ \\
\hline \multicolumn{3}{|l|}{$\begin{array}{l}\text { Men and women } \\
\text { combined }\end{array}$} \\
\hline \multicolumn{3}{|c|}{ Racial harassment } \\
\hline None & $1 \cdot 00$ & $1 \cdot 00$ \\
\hline Verbal & $2 \cdot 30(1 \cdot 48-3 \cdot 57)$ & $2 \cdot 18(1 \cdot 31-3 \cdot 63)$ \\
\hline Physical & $2 \cdot 62(1 \cdot 11-6 \cdot 14)$ & $2.94(1 \cdot 14-7 \cdot 57)$ \\
\hline \multicolumn{3}{|c|}{$\begin{array}{l}\text { Employment-related } \\
\text { discrimination }\end{array}$} \\
\hline No & $1 \cdot 00$ & $1 \cdot 00$ \\
\hline Yes & $1 \cdot 47(1 \cdot 03-2 \cdot 08)$ & $1 \cdot 40(0 \cdot 89-2 \cdot 21)$ \\
\hline \multicolumn{3}{|l|}{$\begin{array}{l}\text { British employers } \\
\text { are racist }\end{array}$} \\
\hline No & $1 \cdot 00$ & $1 \cdot 00$ \\
\hline A few & $1 \cdot 19(0 \cdot 86-1 \cdot 66)$ & $1 \cdot 00(0 \cdot 62-1 \cdot 63)$ \\
\hline About half & $1.92(1.25-2.96)$ & $0.99(0.55-1.80)$ \\
\hline More than half & $2 \cdot 04(1 \cdot 17-3 \cdot 57)$ & $1.79(0.89-3.57)$ \\
\hline
\end{tabular}

CMD, but in all cases the odds ratios indicated increased risk.

Reporting any racially motivated abuse or assault in the last year was associated with between a two- and three-and-a-half-fold increased risk of psychosis among each of the ethnic minority groups, with the exception of Bangladeshi people who exhibited an almost eight-fold increased risk. Reporting experience of employment-related discrimination and perceiving half or more of British employers to be racist appeared to have varying effects on risk of psychosis.

\section{DISCUSSION}

These multivariate analyses suggest that the selfreported experience of interpersonal racism (specifically, verbal abuse, physical assault and racism in access to or within the workplace) and perceiving racism in wider British society - here measured through a belief in the discriminatory motivations of British employers' recruitment practices - each have independent effects on the likelihood of reaching the case threshold for both CMD and psychosis, as measured by the CIS-R and estimated from PSQ scores. In the combined gender and ethnic minority group multivariate models (which included all three measures of exposure to racism and were adjusted for age, household occupational class and current employment status, and gender), experience of racially motivated verbal abuse or physical assault was associated with between a two- and threefold increase in the risk of CMD and psychosis. Reporting experience of employment-related discrimination was associated with an almost $50 \%$ additional increased risk. Believing the majority of British employers to be discriminatory was associated with around a twofold increase in risk. These findings support earlier research which has found a positive association between racism and (mental and physical) ill health (Krieger, 1990, 2000; Krieger \& Sidney, 1996; Karlsen \& Nazroo, 2002).

There appeared to be some variation in the findings for the two indicators of mental health, and among the different ethnic groups included. But the size of the confidence intervals and the fact that some indicators showed a statistical association for all ethnic minority groups combined, but not for the groups separately, suggests that the small number of cases in some cells may have affected our findings. Overall, the models showed consistency across the 
Table 4. Odds ratios for associations between estimated weekly prevalence of common mental disorders (CMD), estimated annual prevalence of psychosis and indicators of racism, gender, age and social class (ethnic minority groups only, men and women combined, standardized for age, gender and socio-economic status)

\begin{tabular}{|c|c|c|c|c|c|}
\hline & Irish & Caribbean & Bangladeshi & Indian & Pakistani \\
\hline \multicolumn{6}{|c|}{ Estimated weekly prevalence of CMD } \\
\hline \multicolumn{6}{|l|}{ Racial harassment } \\
\hline None & $1 \cdot 00$ & $1 \cdot 00$ & $1 \cdot 00$ & $1 \cdot 00$ & $1 \cdot 00$ \\
\hline Verbal or physical & $2 \cdot 86(1 \cdot 31-6 \cdot 25)$ & $2 \cdot 03(1 \cdot 15-3 \cdot 59)$ & $1 \cdot 51(0 \cdot 55-4 \cdot 18)$ & $2 \cdot 70(1 \cdot 32-5 \cdot 56)$ & $2 \cdot 21(1 \cdot 14-4 \cdot 27)$ \\
\hline \multicolumn{6}{|c|}{ Employment-related discrimination } \\
\hline No & $1 \cdot 00$ & $1 \cdot 00$ & $1 \cdot 00$ & $1 \cdot 00$ & $1 \cdot 00$ \\
\hline Yes & $2 \cdot 12(0 \cdot 98-4 \cdot 62)$ & $2 \cdot 08(1 \cdot 27-3 \cdot 43)$ & $3 \cdot 52(1 \cdot 09-11 \cdot 40)$ & $2 \cdot 17(1 \cdot 14-4 \cdot 12)$ & $1 \cdot 15(0 \cdot 60-2 \cdot 22)$ \\
\hline \multicolumn{6}{|l|}{ British employers are racist } \\
\hline None/a few & $1 \cdot 00$ & $1 \cdot 00$ & $1 \cdot 00$ & $1 \cdot 00$ & $1 \cdot 00$ \\
\hline About half/more than half & $2 \cdot 71(1 \cdot 51-4 \cdot 87)$ & $1 \cdot 37(0 \cdot 85-2 \cdot 20)$ & $1 \cdot 84(0 \cdot 77-4 \cdot 44)$ & $1 \cdot 02(0 \cdot 54-1 \cdot 92)$ & $1 \cdot 38(0 \cdot 81-2 \cdot 34)$ \\
\hline \multicolumn{6}{|c|}{ Estimated annual prevalence of psychosis } \\
\hline \multicolumn{6}{|l|}{ Racial harassment } \\
\hline None & $1 \cdot 00$ & $1 \cdot 00$ & $1 \cdot 00$ & $1 \cdot 00$ & $1 \cdot 00$ \\
\hline Verbal or physical & $2 \cdot 26(0 \cdot 62-8 \cdot 23)$ & $3 \cdot 45(1 \cdot 73-6 \cdot 90)$ & $7 \cdot 83(2 \cdot 00-30 \cdot 61)$ & $2 \cdot 16(0 \cdot 87-5 \cdot 38)$ & $3 \cdot 36(1 \cdot 58-7 \cdot 18)$ \\
\hline \multicolumn{6}{|c|}{ Employment-related discrimination } \\
\hline No & $1 \cdot 00$ & $1 \cdot 00$ & $1 \cdot 00$ & $1 \cdot 00$ & $1 \cdot 00$ \\
\hline Yes & $0 \cdot 79(0 \cdot 18-3 \cdot 49)$ & $1 \cdot 40(0 \cdot 74-2 \cdot 67)$ & $0 \cdot 90(0 \cdot 16-4 \cdot 92)$ & $1 \cdot 40(0 \cdot 55-3 \cdot 60)$ & $2 \cdot 23(0 \cdot 75-6 \cdot 60)$ \\
\hline \multicolumn{6}{|l|}{ British employers are racist } \\
\hline None/a few & $1 \cdot 00$ & $1 \cdot 00$ & $1 \cdot 00$ & $1 \cdot 00$ & $1 \cdot 00$ \\
\hline About half/more than half & $1 \cdot 07(0 \cdot 38-3 \cdot 06)$ & $2 \cdot 34(1 \cdot 28-4 \cdot 28)$ & $1 \cdot 12(0 \cdot 25-5 \cdot 03)$ & $0 \cdot 74(0 \cdot 27-2 \cdot 08)$ & $1 \cdot 01(0 \cdot 44-2 \cdot 30)$ \\
\hline
\end{tabular}

ethnic groups studied, including the white Irish group.

When interpreting these findings, some issues should be borne in mind. The proportions of people reporting experience of racism may appear low. The only other large-scale populationbased survey of people from different ethnic groups in England found similar rates of reported racist experiences to those found here (Virdee, 1997; Karlsen \& Nazroo, 2002). The low rates may be because the questioning was restricted to experiences occurring only in the last year. There may also be reasons why people may not report the discrimination they experience: people may not wish to discuss an experience (Parker et al. 1995), or people's interpretations of whether an experience is evidence of racism or not may vary (Taylor et al. 1990; Ruggiero \& Taylor, 1995; Dovido \& Gaertner, 2000). There is evidence to suggest that the way in which someone responds to the discrimination they experience will also influence its impact on health (James et al. 1987; Krieger, 1990; Taylor et al. 1990; Ruggiero \& Taylor, 1995; Krieger \& Sidney, 1996).

As described earlier, the assessment of both CMD and psychosis symptoms used checklist questionnaires, rather than a rigorous clinical assessment. Nevertheless, the instruments used are well established and have been shown to correlate strongly with clinical measures. However, their use in cross-cultural research is less certain.

Determining any causal pathway is impossible using cross-sectional data of this type. This may be a particular issue when exploring the relationship between racism and mental health, as it could be envisaged both that poor mental health (or particular conditions) may lead to greater perception of hostility and that more experiences and perceptions of hostility could produce mental health problems. Determining more definitively whether it is experiences of racism that influence mental health, or if symptoms of depression or psychosis predispose an individual towards increased perception (or experiences) of racism (or both) will require the use of longitudinal data.

Despite these limitations, the findings suggest that experiences of verbal abuse, physical assault, workplace discrimination and perceptions of an inherent racism in British society, are independently associated with prevalence of CMD and risk of psychosis and that the 
experience of social inequality associated with ethnic minority status makes a large contribution to the risk of mental ill health. These findings provide substantial support for the argument that we will continue to be frustrated in our attempts to determine the underlying causes of ethnic differences in mental health until we can properly account for the impact of racism.

\section{ACKNOWLEDGEMENTS}

This work was funded by the Department of Health, UK.

\section{DECLARATION OF INTEREST}

None.

\section{REFERENCES}

Bebbington, P. \& Nayani, Y. (1995). The psychosis screening questionnaire. International Journal of Social Psychiatric Research 5, 11-19.

Berthoud, R. \& Nazroo, J. (1997). The mental health of ethnic minorities. New Community 23, 309-314.

Bhugra, D., Hilwig, M., Hossein, B., Marceau, H., Neehall, J., Leff, J., Mallett, R. \& Der, G. (1996). First contact incidence rates of schizophrenia in Trinidad and one-year follow up. British Journal of Psychiatry 169, 587-592.

Bhugra, D., Leff, J., Mallet, R., Der, G., Corridan, B. \& Rudge, S. (1997). Incidence and outcome of schizophrenia in whites, African-Caribbeans and Asians in London. Psychological Medicine 27, 791-798.

Boydell, J., van Os, J., McKenzie, K., Allardyce, J., Goel, R., McCreadie, R. G. \& Murray, R. M. (2001). Incidence of schizophrenia in ethnic minorities in London: ecological study into interactions with environment. British Medical Journal 323, 1-4.

Brown, C. \& Richie, J. (1982). Focussed Enumeration. The Development of a Method for Sampling Ethnic Minority Groups. PSI/SCPR: London.

Chakraborty, A. \& McKenzie, K. (2002). Does racial discrimination cause mental illness? British Journal of Psychiatry 180, 475-477.

Dovidio, J. F. \& Gaertner, S. L. (2000). Aversive racism and selection decisions: 1989 and 1999. Psychological Science 11, 315-319.

Erens, B., Primatesta, P. \& Prior, G. (2001). Health Survey for England 1999: The Health of Minority Ethnic Groups. TSO: London.

Goldberg, D. P., Cooper, B., Eastwood, M. R., Kenward, H. B. \& Shephard, M. (1970). Standardized psychiatric interview for use in community surveys. British Journal of Preventive and Social Medicine 24, 18-23.

Hickling, F. W. \& Rodgers-Johnson, P. (1995). Incidence of first contact schizoprenia in Jamaica. British Journal of Psychiatry 167, 193-196.

HMSO (1992). 1991 Census Definitions Great Britain. HMSO: London.

James, S. A., Strogatz, D. S., Wing, S. B. \& Ramsey, D. L. (1987). Socioeconomic status, John Henryism and hypertension in blacks and whites. American Journal of Epidemiology 126, 664-673.

Janssen, I., Hanssen, M., Bak, M., Bijl, R. V., De Graaf, R., Vollebergh, W., McKenzie, K. \& van Os, J. (2003). Discrimination and delusional ideation. British Journal of Psychiatry 182, 71-76.
Karlsen, S. \& Nazroo, J. Y. (2002). The relationship between racial discrimination, social class and health among ethnic minority groups. American Journal of Public Health 92, 624-631.

King, M., Coker, E., Leavey, G., Hoare, A. \& Johnson-Sabine, E. (1994). Incidence of psychotic illness in London: comparison of ethnic minority groups. British Medical Journal 309, 1115-1119.

King, M., Nazroo, J., Weich, S., McKenzie, K., Bhui, K., Karlsen, S., Stansfeld, S., Tyrer, P., Blanchard, M., Lloyd. K., McManus, S., Sproston, K. \& Erens, B. (2005). Psychotic symptoms in the general population of England: a comparison of ethnic groups (the EMPIRIC study). Social Psychiatry and Psychiatric Epidemiology 40, 375-381.

Krieger, N. (1990). Racial and gender discrimination: risk factors for high blood pressure? Social Science and Medicine 30, 1273-1281.

Krieger, N. (2000). Discrimination and Health. In Social Epidemiology (ed. L. Berkman and I. Kawachi), pp. 36-75. Oxford University Press: Oxford.

Krieger, N. \& Sidney, S. (1996). Racial discrimination and blood pressure: the CARDIA study of young black and white adults. American Journal of Public Health 86, 1370-1378.

Lewis, G., Pelosi, A. J., Araya, R. C. \& Dunn, G. (1992). Measuring psychiatric disorder in the community: a standard assessment for use by lay interviewers. Psychological Medicine 22, 465-486.

Mahy, G. E., Mallet, R., Leff, J. \& Bhugra, D. (1999). First contact incidence-rate of schizophrenia on Barbados. British Journal of Psychiatry 175, 28-33.

McKenzie, K., van Os, J., Fahy, T., Jones, P., Harvey, I., Toone, B. \& Murray, R. (1995). Psychosis with good prognosis in AfroCaribbean people now living in the United Kingdom. British Medical Journal 311, 1325-1327.

Nazroo, J. Y. (1997). Ethnicity and mental health. Policy Studies Institute: London.

Nazroo, J. \& King, M. (2002). Psychosis - symptoms and estimated rates. In Ethnic Minority Psychiatric Illness Rates in the Community (EMPIRIC) (ed. K. Sproston and J. Nazroo), pp. 47-62. TSO: London.

Parker, H., Botha, J. L. \& Haslam, C. (1995). 'Racism' as a variable in health research - can it be measured? Journal of Epidemiology and Community Health 48, 522.

Ruggiero, K. M. \& Taylor, D. M. (1995). Coping with discrimination: how disadvantaged group members perceive the discrimination that confronts them. Journal of Personality and Social Psychology 68, 826-838.

Sharpley, M., Hutchinson, G., Murray, R. M. \& McKenzie, K. (2001) Understanding the excess of psychosis among the AfricanCaribbean population in England: review of current hypotheses. British Journal of Psychiatry 178 (suppl. 40), S60-S68.

Singleton, N., Bumpstead, R., O'Brien, M., Lee, A. \& Meltzer, H. (2001). Psychiatric morbidity among adults living in private households, 2000. HMSO: London.

Smith, P. \& Prior, G. (1997). The Fourth National Survey of Ethnic Minorities: Technical Report. Social and Community Planning Research: London.

Sproston, K. \& Nazroo, J. (2002). Ethnic Minority Psychiatric Illness Rates in the Community (EMPIRIC). TSO: London.

Sugarman, P. A. \& Craufurd, D. (1994). Schizophrenia in the Afro-Caribbean community. British Journal of Psychiatry 164, 474-480.

Taylor, D. M., Wright, S. C., Moghaddam, F. M. \& Lalonde, R. (1990). The personal/group discrimination discrepancy: perceiving my group, but not myself, to be a target of discrimination. Personality and Social Psychology Bulletin 16, 254-262.

van Os, J., Castle, D., Takei, N., Der, G. \& Murray, R. M. (1996). Psychotic illness in ethnic minorities: clarification from the 1991 Census. Psychological Medicine 26, 203-208.

Virdee, S. (1997). Racial harassment. In Ethnic Minorities in Britain: Diversity and Disadvantage (ed. T. Modood, R. Berthoud, J. Lakey, J. Nazroo, P. Smith, S. Virdee and S. Beishon), pp 259-289. Policy Studies Institute: London.

Weich, S. \& McManus, S. (2002). Common mental disorders. In Ethnic Minority Psychiatric Illness Rates in the Community 
(EMPIRIC) (ed. K. Sproston and J. Nazroo), pp. 25-46. TSO: London.

Weich, S., Nazroo, J., Sproston, K., McManus, S., Blanchard, M., Erens, B., Karlsen, S., King, M., Lloyd, K., Stansfeld, S. \& Tyrer, P. (2004). Common mental disorders and ethnicity in England: the EMPIRIC Study. Psychological Medicine 34, 1543-1551.
Williams, R. \& Hunt, K. (1997). Psychological distress among British South Asians: the contribution of stressful situations and subcultural differences in the West of Scotland Twenty-07 Study. Psychological Medicine 27, 1173-1181.

Wing, J. K., Cooper, J. E. \& Sartorius, N. (1974). Measurement and Classification of Psychiatric Symptoms. Cambridge University Press: Cambridge. 